\title{
Peer Victimization and Academic Performance in Primary School Children
}

\section{Mundy, Lisa K.}

2017

Mundy , L K , Canterford , L , Kosola , S , Degenhardt , L , Allen , N B \& Patton , G C 2017 , '

Peer Victimization and Academic Performance in Primary School Children ' , Academic

Pediatrics , vol. 17 , no. 8 , pp. 830-836 . https://doi.org/10.1016/j.acap.2017.06.012

http://hdl.handle.net/10138/298121

https://doi.org/10.1016/j.acap.2017.06.012

publishedVersion

Downloaded from Helda, University of Helsinki institutional repository.

This is an electronic reprint of the original article.

This reprint may differ from the original in pagination and typographic detail.

Please cite the original version. 


\title{
Peer Victimization and Academic Performance in Primary School Children
}

\author{
Lisa K. Mundy, PhD; Louise Canterford, MBiostat; Silja Kosola, MD; Louisa Degenhardt, PhD; \\ Nicholas B. Allen, PhD; George C. Patton, MD
}

From the Murdoch Children's Research Institute (Drs Mundy, Canterford, and Patton), Centre for Adolescent Health (Drs Mundy, Canterford, and Patton), The Royal Children's Hospital, Department of Paediatrics (Drs Mundy, and Patton), The University of Melbourne, Victoria, National Drug and Alcohol Research Centre (Dr Degenhardt), University of New South Wales, Australia; School and Student Healthcare (Dr Kosola), City of Helsinki and University of Helsinki, Finland; and Department of Psychology (Dr Allen), University of Oregon, Eugene The authors have no conflicts of interest to disclose.

Address correspondence to Lisa K. Mundy, PhD, Centre for Adolescent Health, The Royal Children's Hospital, Flemington Road, Victoria 3052, Australia (e-mail: lisa.mundy@mcri.edu.au).

Received for publication January 23, 2017; accepted June 17, 2017.

\section{AbStRAct}

OBJECTIVE: Peer victimization is a common antecedent of poor social and emotional adjustment. Its relationship with objectively measured academic performance is unclear. In this study we aimed to quantify the cross-sectional associations between peer victimization and academic performance in a large population sample of children.

METHODS: Eight- to 9-year-old children were recruited from a stratified random sample of primary schools in Australia. Academic performance was measured on a national achievement test (1 year of learning equals 40 points). Physical and verbal victimization were measured according to child self-report.

RESULTS: Multilevel mixed-effects linear regression analyses were conducted. For female children, verbal victimization was associated with poorer academic performance on writing $(\beta=17.2 ; 95 \%$ confidence interval $[\mathrm{CI}],-28.2$ to -6.2$)$ and grammar/punctuation ( $\beta=-20.8 ; 95 \% \mathrm{CI},-40.1$ to -1.6 ). Physical victimization was associated with poorer performance on numeracy (male children: $\beta=-29.0 ; 95 \% \mathrm{CI},-53.8$ to -4.1 ; female children: $\beta=-30.1$; $95 \% \mathrm{CI},-56.6$ to -3.5 ), and writing (female children: $\beta=-21.5 ; 95 \% \mathrm{CI},-40.4$ to -2.7). Verbal and physical victimization were associated with poorer performance on reading (male children: $\beta=-31.5$; $95 \% \mathrm{CI},-59.9$ to -3.1 ; female children: $\beta=-30.2 ; 95 \%$ CI, -58.6 to -1.8 ), writing (female children: $\beta=-25.5$; $95 \% \mathrm{CI},-42.8$ to -8.2 ), spelling (female children: $\beta=-32.3 ; 95 \% \mathrm{CI},-59.6$ to -4.9$)$, and grammar/punctuation (female children: $\beta=-32.2 ; 95 \% \mathrm{CI},-62.4$ to -2.0 ).

Conclusions: Children who were physically victimized were 6 to 9 months behind their non-victimized peers on measures of academic performance. There are growing reasons for education systems to invest in the prevention of bullying and promotion of positive peer relationships from the earliest years of school.

Keywords: bullying; Childhood to Adolescence Transition Study (CATS); education; peer victimization; public health

Academic Pediatrics 2017;17:830-836

\section{What's NeW}

This is the first large population-based study to quantify associations between physical and verbal victimization with a national test of achievement. Children who were physically victimized in midprimary school were 6 to 9 months behind their non-victimized peers on measures of academic performance.

BULLYING IS A worldwide public health problem, with up to 1 in 3 students across the world experiencing regular victimization, although prevalence varies across countries. ${ }^{1}$ Bullying is defined as repeated negative actions toward another child intended to cause harm; there is typically an imbalance of power between the victim and bully. ${ }^{2}$ Bullying can take many forms, including physical victimization (pushing and hitting) and verbal victimization (teasing and threatening), as well as relational bullying (social exclusion). Rates peak during the mid to late primary school years and decline with age. ${ }^{3}$ Boys are more likely to be physically victimized, and girls are more likely to be involved in relational bullying. No gender differences have been observed for verbal victimization. ${ }^{4}$ The consequences of bullying are serious, with victims at increased risk of mental health problems, including self-harm and suicide. ${ }^{5,6}$ The effect of childhood bullying persists into later life, affecting not only mental health but also secondary school completion and employment outcomes. ${ }^{7,8}$

Schools have increasingly started to address bullying, through the use of a number of programs, with some success. ${ }^{9}$ However, a substantial number of children continue to experience peer victimization in school. ${ }^{10}$ Victims of bullying have lower rates of school engagement and higher rates of absenteeism. ${ }^{11}$ Although some evidence suggests a 
relationship between being bullied and academic performance, findings from a meta-analysis of 33 studies showed that the pattern is inconsistent, which might be in part a result of methodological differences. ${ }^{12}$ Understanding this relationship, particularly in midprimary school, might be especially important, because academic difficulties during these years predict later academic failure and school dropout. ${ }^{13}$ A limitation of most previous studies is the focus on bullying in early childhood or adolescence as opposed to the middle years, and the inclusion of a wide age range of participants spanning multiple school stages. ${ }^{10,14}$

Gender differences, which have rarely been examined, might also explain the conflicting results in previous studies. Some studies have reported the effect to be stronger for boys, whereas other studies have reported the effect to be stronger in girls. ${ }^{12}$ Although a meta-analysis showed that the effect of gender was not significant, the authors suggest this finding should be treated with caution because gender differences might exist at certain ages or stages of school but this could not be explored in the meta-analysis. ${ }^{12}$ Because gender differences have been observed in the prevalence of bullying as well as in academic performance, ${ }^{4,15}$ understanding whether the bullying and academic performance relationship differs according to gender is an important consideration.

Although some studies have considered the type of victimization, ${ }^{16}$ much research has focused on global measures of victimization, which might contribute to the inconsistent findings. ${ }^{12}$ As far as we are aware, no studies have examined differences between direct bullying (verbal and physical), with most studies grouping these together. Some studies have compared direct bullying with relational bullying, but there has been no clear pattern. ${ }^{12}$ Another limitation of previous studies is that only a limited number of small studies have considered the role of emotional problems. ${ }^{16,17}$ It has been suggested that peer victimization might contribute to poor academic performance through emotional problems. ${ }^{10}$

The aim of this study was to quantify the associations between peer victimization and academic performance in a large population sample of children in midprimary school, a phase when peer problems and risks for school disengagement are increasing. We specifically examined associations between verbal and physical victimization with academic performance. Socioeconomic status (SES) is known to be associated with victimization as well as academic performance, and was controlled in analyses. ${ }^{18,19}$ Analyses were stratified according to gender to investigate the potential modifying effect of gender. In secondary analyses, we also controlled for emotional symptoms. It was hypothesised that peer victimization would be associated with academic performance.

\section{METHODS}

\section{Study Population and Design}

Data for this study (collected between June and November 2012) were drawn from the first wave of the Childhood to Adolescence Transition Study (CATS), which is a cohort study with a broad focus on health, education, and social adjustment. This study was funded from Australia's National Health and Medical Research Council (NHMRC). The full study design is reported elsewhere. ${ }^{20}$ Briefly, children were selected from a stratified random sample of 43 government (public) and nongovernment (private) primary schools (government, Catholic, independent strata) in metropolitan Melbourne, Australia. If a school did not consent to participate, a replacement school was randomly selected from the same stratum and offered participation. All grade 3 children (8-9 years of age; the fourth year of formal schooling) in the selected schools were invited to participate. There were no inclusion or exclusion criteria. Of the 2289 invited children, $1239(54 \%)$ were recruited through the provision of active, informed parent consent. The main reason for nonrecruitment was parents failing to return the consent form. Of the parents who gave consent, 1147 (93\%) provided additional optional consent to link with their child's National Assessment Program-Literacy and Numeracy (NAPLAN) results.

The sample of students who had parental consent contained a slightly smaller proportion of male than female students (46\% male; $54 \%$ female) compared with matched census data (51\% male; $49 \%$ female) ${ }^{21}$ This sample scored slightly higher on SES (Socio-Economic Index for Areas [SEIFA]) compared with the Australian population $($ mean $=1012 ; \mathrm{SD}=67$ vs mean $=1000 ; \mathrm{SD}=100)$.

\section{Procedure}

The student assessment included a student questionnaire, which was completed in a class setting with a research assistant reading the questions aloud. Parents completed a paper questionnaire at the same time as the consent process. Ethics approval was granted by the Royal Children's Hospital Human Research Ethics Committee (31089). Permission was granted from the Victorian Department of Education and Early Childhood Development Office and the Catholic Education Office Melbourne to recruit through their schools.

\section{Measures}

\section{Academic Performance}

A national achievement test was used as a measure of academic performance. NAPLAN assesses academic performance on 5 domains: reading, writing, numeracy, spelling, and grammar/punctuation. NAPLAN is administered to all students in schools across Australia in grades $3,5,7$, and 9 . A score ranging from 0 to 1000 is provided for each domain completed by each child and this score is scaled across all grades. ${ }^{22}$ This means all student results across year levels 3 to 9 are located on a single scale and so student achievement over time can be easily measured. Grade 3 students with a score lower than 270 are considered to perform below the national minimum standard. The mean score between grades 3 and 5 increases by approximately 80 points, thus, as a guide, 1 year of learning between grades 3 and 4 equals approximately 40 NAPLAN points. ${ }^{22}$ NAPLAN data were provided by the Victorian Curriculum and Assessment Authority. 


\section{Peer Victimization}

Peer victimization was measured via child self-report with selected items from the Gatehouse Bullying Scale, which is a short, reliable scale for measuring bullying in schools. ${ }^{23}$ These items assessed physical victimization (have you been hurt like being hit or kicked by another student?) and verbal victimization (has anyone teased you or called you names?) in the past month. Students responding 'yes' were then asked how often they had each experience (response options 'less than once a week,' 'about once a week,' 'most days'). In line with previous research, children were classified as 'frequently physically bullied' if they reported facing physical victimization 'about once a week' or on 'most days. ${ }^{24}$ Children were classified as 'frequently verbally bullied' if they reported being verbally victimized about 'once a week' or on 'most days.' A summary measure of peer victimization was generated: 'not frequently victimized (none)'; 'frequently verbally victimized (verbal only),' 'frequently physically victimized (physical only),' and 'frequently both verbally and physical victimized (verbal as well as physical).'

\section{Covariates}

To assess potential confounding, the following variables, chosen a priori, were included in the analyses.

Family SES was assigned from small area deprivation measures calculated for home postcode using the Index of Relative Socio-economic Advantage and Disadvantage (population mean $=1000 ; \mathrm{SD}=100$ ) from the Australian Bureau of Statistics census-based local neighborhood SEIFA. ${ }^{25}$ Higher scores on this measure indicate higher SES.

Parent report on the emotional symptoms subscale of the Australian version of the Strengths and Difficulties Questionnaire (SDQ) was used to assess child emotional symptoms. ${ }^{26}$ The SDQ consists of 25 items divided between 5 scales: emotional symptoms, conduct problems, hyperactivity/inattention, peer relationship problems, and prosocial behavior. Parents rate each of the items as 'Not True,' 'Somewhat True,' or 'Certainly True.' 'Somewhat True' is always scored as 1 but the scoring of 'Not True' and 'Certainly True' varies according to item as 0 or 2 . The emotional symptoms SDQ subscale score can range from 0 to 10 and this subscale was used in the current study. Higher scores indicate higher levels of emotional symptoms.

Additional demographic characteristics were used to describe the sample. Information about a child's indigenous status (Aboriginal and Torres Strait Islander) and country of birth (Australia or other) was obtained in the parent questionnaire.

\section{Data Analysis}

Child characteristics, family SES, school type, peer victimization, and academic performance were summarized and compared according to sex. Means (SDs) were calculated for continuous measures and compared using $t$ tests. Percentages were calculated for categorical variables and compared using chi-square tests. Multilevel mixed effects linear regression models were used to investigate the associations between peer victimization (4-level exposure variable: 'not frequently victimized [none],' 'frequently verbally victimized (verbal only),' 'frequently physically victimized (physical only),' and 'frequently both verbally and physically victimized [verbal as well as physical]') on each NAPLAN score, and to account for clustering by schools. Effects were estimated separately for boys and girls, because of gender differences that have been observed in the prevalence of bullying as well as in academic performance. Two sets of analyses were conducted: 1) adjusting for child's age (in months; centered about the mean), and family SEIFA score, 2) adjusted for the aforementioned variables, and for child's emotional symptoms SDQ score. Data analysis was undertaken using Stata 14 (Stata Corp, College Station, TX).

\section{RESULTS}

Of the children who provided consent, 1194 (96\%) completed a survey and $1178(95 \%)$ completed the peer victimization items. Of the parents who provided consent to link with NAPLAN, NAPLAN results were not available for $103(9 \%)$ of these students. The reasons for these missing data were the student was: absent $(11 ; 1 \%)$, exempt $(8 ; 1 \%)$, withdrawn $(10 ; 1 \%)$, or the data were not matched (74; 6\%). A parent questionnaire was completed for most of the recruited students (1218; 98\%); SDQ emotional symptoms items were completed for 1205 (97\%) students. Students were excluded from the analysis sample if they did not have at least 1 NAPLAN score and/or did not complete the peer victimization items $(n=241 ; 19.4 \%$ of the recruited students). A further $\mathrm{n}=24(1.9 \%)$ were excluded because they did not have complete data for the SDQ emotional symptoms scale. Children who were younger than 8 years and those who were 10 years of age or older at the time of the assessment $(n=9 ; 0.7 \%)$ were then excluded. This resulted in an analysis sample of 965 (44.8\% male) students. There was no evidence for a difference in gender $(P=.06)$, and school sector $(P=.12)$ between the analysis sample and those excluded. However, a greater proportion of the excluded sample was disadvantaged $(P=.001)$ and the mean age was slightly higher for the excluded sample $(P=.005)$.

Child characteristics and family SES were similar for male and female participants (Table 1). One in 3 boys reported being bullied frequently, with almost 1 in 5 reporting frequently experiencing physical victimization and 1 in 4 experiencing verbal victimization. One in 10 boys reported being verbally as well as physically bullied frequently. Slightly lower rates were observed in girls $(P=.007)$, with more than 1 in 4 girls reporting being frequently bullied; 1 in 10 experienced frequent physical victimization and nearly 1 in 4 experiencing verbal victimization. More than 1 in 20 girls reported being both verbally and physically bullied frequently.

NAPLAN results in the analysis sample aligned with results for the Victoria metropolitan area presented in the 2012 national report (means: reading 436.2; numeracy 
Table 1. Summary of Demographic Characteristics, Peer Victimization, and Academic Performance Among 8- to 9-Year-Old Grade 3 Children $(n=965)$, Stratified According to Sex

\begin{tabular}{|c|c|c|c|c|c|c|c|}
\hline \multirow[b]{2}{*}{ Measure } & \multicolumn{3}{|c|}{ Male } & \multicolumn{3}{|c|}{ Female } & \multirow[b]{2}{*}{$P^{\star}$} \\
\hline & $\mathrm{N}$ & $\mathrm{n}$ & Value & $\mathrm{N}$ & $\mathrm{n}$ & Value & \\
\hline \multicolumn{8}{|l|}{ Children's characteristic } \\
\hline Mean age (SD), years & 432 & & $9.0(0.4)$ & 533 & & $9.0(0.3)$ & .81 \\
\hline Australian born, \% & 426 & 378 & 88.7 & 531 & 473 & 89.1 & .87 \\
\hline ATSI, \% & 427 & 25 & 5.9 & 528 & 21 & 4.0 & .18 \\
\hline $\begin{array}{l}\text { Mean emotional symptoms } \\
\text { (SDQ) (SD) }\end{array}$ & 432 & & $2.0(2.0)$ & 533 & & $2.3(2.1)$ & .08 \\
\hline \multicolumn{8}{|l|}{ Family characteristics } \\
\hline SEIFA (IRSAD) score quintile (\%) & 432 & & & 533 & & & .15 \\
\hline $\begin{array}{l}\text { First quintile (most } \\
\text { disadvantaged) }\end{array}$ & & 48 & 11.1 & & 64 & 12.0 & \\
\hline Second quintile & & 25 & 5.8 & & 54 & 10.1 & \\
\hline Third quintile & & 74 & 17.1 & & 79 & 14.8 & \\
\hline Fourth quintile & & 123 & 28.5 & & 148 & 27.8 & \\
\hline $\begin{array}{c}\text { Fifth quintile (most } \\
\text { advantaged) }\end{array}$ & & 162 & 37.5 & & 188 & 35.3 & \\
\hline \multicolumn{8}{|l|}{ School characteristic } \\
\hline Education sector, \% & 432 & & & 533 & & & .009 \\
\hline Government & & 294 & 68.1 & & 388 & 72.8 & \\
\hline Catholic & & 124 & 28.7 & & 114 & 21.4 & \\
\hline Independent & & 14 & 3.2 & & 31 & 5.8 & \\
\hline Frequent peer victimization, \% & 432 & & & 533 & & & .007 \\
\hline None & & 288 & 66.7 & & 388 & 72.8 & \\
\hline Verbal only & & 65 & 15.1 & & 89 & 16.7 & \\
\hline Physical only & & 35 & 8.1 & & 25 & 4.7 & \\
\hline Verbal as well as physical & & 44 & 10.2 & & 31 & 5.8 & \\
\hline \multicolumn{8}{|l|}{ Academic performance } \\
\hline \multicolumn{8}{|l|}{ Mean NAPLAN score (SD) } \\
\hline Reading & 430 & & $441.1(91.3)$ & 527 & & $447.1(81.5)$ & .29 \\
\hline Numeracy & 423 & & $431.5(74.7)$ & 523 & & $411.9(69.4)$ & $<.001$ \\
\hline Writing & 426 & & $425.6(55.7)$ & 526 & & $449.5(50.2)$ & $<.001$ \\
\hline Spelling & 427 & & $425.1(79.3)$ & 526 & & $440.5(75.4)$ & .002 \\
\hline Grammar and punctuation & 427 & & $437.5(91.2)$ & 526 & & $458.4(85.3)$ & .0003 \\
\hline
\end{tabular}

ATSI indicates Aboriginal and Torres Strait Islander; IRSAD, Index of Relative Socio-Economic Advantage and Disadvantage; NAPLAN, National Assessment Program-Literacy and Numeracy; SDQ, Strengths and Difficulties Questionnaire; and SEIFA, Socio-Economic Indexes for Areas.

${ }^{*}$ Chi-square tests were applied to the categorical variables and independent-samples $t$ tests to the continuous variables; tests were applied to determine if there were any gender difference for the variables.

412.8; writing 432.6; spelling 429.8; grammar/punctuation 443.2). ${ }^{22}$ Boys scored significantly higher on the NAPLAN numeracy domain than girls, whereas NAPLAN reading scores were similar between boys and girls (Table 1). Girls scored significantly higher on the other NAPLAN domains (writing, spelling, and grammar/punctuation) than boys (Table 1).

Two-level models, adjusting for age (in months, centered about the mean) and SEIFA score (in quintiles) and with school clusters as the group level, were used to assess the cross-sectional association of peer victimization (verbal only vs. none; physical only vs. none; verbal as well as physical vs. none) with each of the 5 NAPLAN domains (Table 2). For boys, no associations between experiencing only verbal victimization and NAPLAN scores were observed. For boys, experiencing physical victimization only was associated with lower NAPLAN numeracy scores (adjusted mean difference: -29.0 (95\% confidence interval $[\mathrm{CI}],-53.8$ to $-4.1)$ ), which equates to a delay in learning of $>6$ months compared with their non-victimized peers. For boys, experiencing verbal as well as physical victimization was associated with lower NAPLAN reading scores (adjusted mean difference: $-31.5 ; 95 \% \mathrm{CI},-59.9$ to -3.1 ) and NAPLAN scores. It should be noted that there was a trend toward lower NAPLAN scores (across all 5 domains) for boys who experienced physical victimization only, and also for boys who experienced verbal as well as physical victimization.

For girls, experiencing verbal victimization only was associated with lower NAPLAN writing and grammar/ punctuation scores (adjusted mean difference: -17.2; $95 \% \mathrm{CI},-28.2$ to -6.2 ; and $-20.8 ; 95 \% \mathrm{CI},-40.1$ to -1.6 , respectively). This represents a delay of approximately 6 months in learning for girls experiencing verbal victimization compared with their non-victimized peers. For girls, experiencing physical victimization only was associated with lower NAPLAN scores on the numeracy and writing domains (adjusted mean difference: -30.1 ; $95 \% \mathrm{CI},-56.6$ to -3.5 ; and $-21.5 ; 95 \% \mathrm{CI},-40.4$ to -2.7 , respectively). Girls who experienced physical victimization were between 6 and 9 months behind their non-victimized peers across all domains of academic performance. For girls, experiencing verbal as well as physical victimization was associated with lower NAPLAN scores on all but the numeracy domain (Table 2). 
Table 2. Associations Between Continuous NAPLAN Scores With Reported Peer Victimization (Adjusting for Age and SES) in 8- to 9-YearOld Grade 3 Children $(n=965)$

\begin{tabular}{|c|c|c|c|c|c|c|c|c|c|}
\hline \multirow[b]{2}{*}{ NAPLAN Domain } & \multicolumn{3}{|c|}{ Verbal Only Versus None } & \multicolumn{3}{|c|}{ Physical Only Versus None } & \multicolumn{3}{|c|}{ Verbal as Well as Physical Versus None } \\
\hline & $\beta^{*}$ & $95 \% \mathrm{Cl}$ & $P$ & $\beta^{*}$ & $95 \% \mathrm{Cl}$ & $P$ & $\beta^{*}$ & $95 \% \mathrm{Cl}$ & $P$ \\
\hline \multicolumn{10}{|l|}{ Male $†$} \\
\hline Reading & -1.7 & -25.4 to 22.0 & .89 & -17.1 & -48.0 to 13.8 & .28 & -31.5 & -59.9 to -3.1 & .03 \\
\hline Numeracy & 3.2 & -16.1 to 22.4 & .75 & -29.0 & -53.8 to -4.1 & .02 & -18.9 & -41.5 to 3.8 & .10 \\
\hline Writing & -0.1 & -14.4 to 14.2 & .99 & -6.8 & -25.9 to 12.3 & .49 & -7.8 & -24.9 to 9.3 & .37 \\
\hline Spelling & -3.7 & -24.7 to 17.4 & .73 & -22.0 & -50.0 to 6.1 & .12 & -13.2 & -38.3 to 11.8 & .30 \\
\hline Grammar/punctuation & 13.1 & -10.5 to 36.7 & .28 & -25.1 & -56.6 to 6.3 & .12 & -21.4 & -49.5 to 6.7 & .14 \\
\hline \multicolumn{10}{|l|}{ Female $\neq$} \\
\hline Reading & -11.3 & -29.2 to 6.6 & .22 & -30.1 & -61.0 to 0.8 & .06 & -30.2 & -58.6 to -1.8 & .04 \\
\hline Numeracy & -8.6 & -23.9 to 6.7 & .27 & -30.1 & -56.6 to -3.5 & .03 & -13.8 & -38.3 to 10.6 & .27 \\
\hline Writing & -17.2 & -28.2 to -6.2 & .002 & -21.5 & -40.4 to -2.7 & .03 & -25.5 & -42.8 to -8.2 & .004 \\
\hline Spelling & -14.0 & -31.4 to 3.4 & .12 & -9.7 & -39.7 to 20.3 & .53 & -32.3 & -59.6 to -4.9 & .02 \\
\hline Grammar/punctuation & -20.8 & -40.1 to -1.6 & .03 & -23.6 & -56.5 to 9.3 & .16 & -32.2 & -62.4 to -2.0 & .04 \\
\hline
\end{tabular}

IRSAD indicates Index of Relative Socio-Economic Advantage and Disadvantage; NAPLAN, National Assessment Program-Literacy and Numeracy; SEIFA, Socio-Economic Indexes for Areas; and SES, socioeconomic status.

*Mean difference estimated from multilevel linear regression models adjusted for age (in months, centered about the mean), and SEIFA (IRSAD).

†For boys, the sample size ranged from 423 to 430 .

¥For girls, the sample size ranged from 523 to 527 .

Table 3 presents the cross-sectional association of peer victimization with each of the 5 NAPLAN domains adjusting for emotional problems (in addition to adjusting for age [in months, centered about the mean], and SEIFA score) and the patterns of association remained the same.

\section{DISCUSSION}

One in 3 male and one in four female Australian students aged 8 to 9 years reported frequent bullying in the past month. Girls who experienced verbal victimization (but not other forms), scored poorer than their non-victimized peers on dimensions of writing and grammar/punctuation; those associations remained when controlling for emotional symptoms.
Children who were physically victimized by peers were between 6 and 9 months behind their non-victimized peers on a national assessment of numeracy, even after controlling for the child's emotional symptoms. Girls who were verbally as well as physically victimized, were approximately 6 to 9 months behind their non-victimized peers on reading, writing, spelling, and grammar/punctuation. After only 3 full years of schooling, a delay of between 6 to 9 months represents a substantial disadvantage compared with nonvictimized peers.

The effects of victimization were most clear for girls across all domains of academic performance. Verbal bullying was found to be associated with deficits in some domains of academic functioning for girls. Girls who were physically and verbally bullied had poorer performance in all academic domains but numeracy. These

Table 3. Associations Between Continuous NAPLAN Scores With Reported Peer Victimization (Adjusting for Age, SES, and SDQ [Emotional Symptoms subscale score]) in 8- to 9-Year-Old Grade 3 Children $(n=965)$

\begin{tabular}{|c|c|c|c|c|c|c|c|c|c|}
\hline \multirow[b]{2}{*}{ NAPLAN Domain } & \multicolumn{3}{|c|}{ Verbal Only Versus None } & \multicolumn{3}{|c|}{ Physical Only Versus None } & \multicolumn{3}{|c|}{ Verbal as Well as Physical Versus None } \\
\hline & $\beta^{*}$ & $95 \% \mathrm{Cl}$ & $P$ & $\beta^{*}$ & $95 \% \mathrm{Cl}$ & $P$ & $\beta^{*}$ & $95 \% \mathrm{Cl}$ & $P$ \\
\hline \multicolumn{10}{|l|}{ Male† } \\
\hline Reading & -3.0 & -26.2 to 20.3 & .80 & -15.0 & -45.4 to 15.3 & .33 & -31.1 & -58.9 to -3.2 & .03 \\
\hline Numeracy & 2.0 & -16.5 to 20.5 & .83 & -26.8 & -50.7 to -2.8 & .03 & -16.4 & -38.2 to 5.4 & .14 \\
\hline Writing & -0.6 & -14.7 to 13.6 & .94 & -6.1 & -24.9 to 12.7 & .52 & -7.6 & -24.5 to 9.2 & .37 \\
\hline Spelling & -4.5 & -25.1 to 16.2 & .67 & -20.5 & -48.1 to 7.0 & .14 & -13.0 & -37.6 to 11.6 & .30 \\
\hline Grammar/punctuation & 11.9 & -11.0 to 34.7 & .31 & -23.2 & -53.6 to 7.2 & .14 & -20.9 & -48.1 to 6.3 & .13 \\
\hline \multicolumn{10}{|l|}{ Female $\neq$} \\
\hline Reading & -11.3 & -29.2 to 6.7 & .22 & -30.1 & -61.0 to 0.8 & .06 & -30.2 & -58.7 to -1.7 & .04 \\
\hline Numeracy & -8.9 & -24.3 to 6.4 & .25 & -30.0 & -56.5 to -3.4 & .03 & -14.3 & -38.9 to 10.2 & .25 \\
\hline Writing & -17.3 & -28.3 to -6.3 & .002 & -21.5 & -40.3 to -2.6 & .03 & -25.7 & -43.1 to -8.3 & .004 \\
\hline Spelling & -14.2 & -31.7 to 3.3 & .11 & -9.6 & -39.6 to 20.4 & .53 & -32.6 & -60.1 to -5.1 & .02 \\
\hline Grammar/punctuation & -20.2 & -39.5 to -0.9 & .04 & -23.8 & -56.7 to 9.1 & .16 & -31.1 & -61.4 to -0.8 & .04 \\
\hline
\end{tabular}

IRSAD indicates Index of Relative Socio-Economic Advantage and Disadvantage; NAPLAN, National Assessment Program-Literacy and Numeracy; SDQ, Strengths and Difficulties Questionnaire; SEIFA, Socio-Economic Indexes for Areas; and SES, socioeconomic status.

*Mean difference estimated from multilevel linear regression models adjusted for age (in months), SEIFA (IRSAD), and SDQ emotional symptoms subscale score.

†For boys, the sample size ranged from 423 to 430 .

fFor girls, the sample size ranged from 523 to 527 . 
results support previous findings that girls might be more negatively affected by peer victimization than boys. ${ }^{5}$

The failure of previous studies to consider the type of victimization might account for the discrepancies seen in previous research on this topic. ${ }^{12}$ Overall there was a trend for physical bullying (whether or not combined with verbal bullying) to be associated with poorer performance but this trend did not always reach statistical significance, in part because of the relatively small number of participants in the physical victimization groups. The effect sizes for verbal victimization were also smaller than those observed for physical victimization. The results from the current study suggest that physical victimization might be a more severe type of bullying than verbal victimization alone at this phase of life. ${ }^{27}$ Further research is warranted but these results suggest intervention strategies might be most effective if they consider the potential effect of physical bullying.

Although experiencing bullying might have greater adverse consequences for girls, boys typically experience higher rates of bullying. ${ }^{4}$ This pattern was observed in the current study, with approximately one-third of boys reporting frequent bullying compared with one-quarter of girls. Although prevalence estimates vary across the world and vary according to the definitions used and age of children, a recent report suggests that globally, as many as 1 in 3 students experience frequent bullying. ${ }^{1}$ In Australia, it is estimated at least 1 in 7 children are frequently bullied, ${ }^{4}$ but rates are higher in younger age groups with up to 1 in four 9- to 15 -year-old children reporting frequent bullying. ${ }^{28} \mathrm{In}$ the current study, more boys experienced physical (1 in 5) than verbal ( 1 in 6$)$ victimization. In contrast, more girls experienced verbal only victimization (17\%) than physical bullying (11\%), consistent with previous research. ${ }^{29}$

Strengths of this study include the use of an objective national assessment of academic performance, the examination of verbal as well as physical victimization, and the use of multilevel models to adjust for clustering. Most previous studies have used perceptions of academic performance, such as brief teacher reports or even student selfreport, ${ }^{3,30}$ and some studies have used grade point averages obtained from school reports. ${ }^{31}$ Very few studies have used objective measures of academic performance. ${ }^{32}$ A meta-analysis revealed that effect sizes were smaller in magnitude when standardized grades were used compared with grades from school reports, ${ }^{12}$ which is not surprising because studies have reported only moderate correlations between standardized grades and school reports, and teachers might incorporate effort and motivation into classroom grades. ${ }^{12}$ This might in part explain the inconsistencies in past research.

Some limitations of this study should also be considered. An active parental consent process was used at recruitment and only 54\% of parents provided written consent for participation. Even so, our sample was very close to the Australian population mean on SES. Although it is possible that the specification of the association might have differed slightly with a higher response rate, the similarity in outcomes and exposures to popula- tion norms suggests it is unlikely that response bias will have substantially changed the study's findings. ${ }^{4,22}$ The use of student self-reports to assess victimization is also a limitation. A meta-analysis revealed that the use of self-report measures resulted in smaller effect sizes, possibly because of the subjective nature of self-reports and the desire to protect self-esteem. ${ }^{12}$ However, in the current study large effect sizes were found despite the use of self-report measures of victimization. Another limitation is that there was no measure of relational victimization in the current study. We were also unable to control for variables such as school engagement, baseline performance, learning disorders, student enrollment, and peer rejection, which might be associated with victimization and academic performance. ${ }^{12}$

This was a cross-sectional study and so it is not possible to establish causality. It is possible that even at this early stage peer victimization might affect educational attainment. It is also possible that educational failure might in some way heighten the risk of bullying. For example, poor academic performance might lead to lower social status and thus a greater likelihood of becoming a victim of bullying. ${ }^{33}$ Some evidence suggests that the relationship between peer victimization and academic performance may be curvilinear (U-shaped) with students in the midachievement band experiencing less victimization than those in the top or lower bands of achievement. ${ }^{34}$ Alternatively, there may be common underlying factors that influence educational achievement as well as bullying, such as emotional problems and SES. ${ }^{18,19,35}$ However, in the current study, adjustment for emotional problems and SES did little to diminish the associations, but the possibility of confounding cannot be excluded. Also, bullying often occurs within school, which might reduce the victims' connection to school and in turn lead to absences from school, further increasing the risk to academic performance. $^{12}$

Longitudinal analyses will ultimately be needed to understand the long-term effects of peer victimization on students' academic performance. ${ }^{36}$ However, the high rates of peer victimization and the size of the associations with academic performance observed at this early age suggest that preventing bullying should be a key priority for primary schools. The late primary school years are a time when bullying rates peak and risks for school disengagement increase, making this an important phase of life to intervene in the relationship between bullying and academic performance. The results from this study suggest that schools should be aware of verbal as well as physical bullying and bullying programs should consider both forms of bullying, and how they might affect the academic achievement of boys and girls differently. Bullying interventions need to begin in the earliest years of school, before bullying becomes part of the culture. There is evidence that wholeschool interventions are most effective. ${ }^{37}$ Social support from peers has been shown to protect bullied adolescents from poor academic outcomes and might prove beneficial in this younger age group. ${ }^{10}$ 


\section{ACKNOWLEDGMENTS}

The authors thank all of the families and schools who participated in this study, and all staff and volunteers involved in data collection and processing at Murdoch Children's Research Institute.

Financial disclosure: This research was supported by a project grant from Australia's NHMRC (1010018). Murdoch Childrens Research Institute research is supported by the Victorian Government's Operational Infrastructure Program. L.K.M. is partially supported by a grant from the Invergowrie Foundation. G.C.P. is supported by a Senior Principal Research Fellowship from NHMRC and L.D. by an NHMRC Principal Research Fellowship (1041742). The funding sources had no role in study design, in the collection, analysis, or interpretation of data, in the writing of the report, and in the decision to submit the report for publication.

\section{REFERENCES}

1. UNICEF. Hidden in Plain Sight: A Statistical Analysis of Violence Against Children. London: UNICEF; 2014.

2. Olweus D. Bullying or peer abuse at school: facts and intervention. Curr Dir Psychol Sci. 1995;4:196-200.

3. Nansel TR, Overpeck M, Pilla RS, et al. Bullying behaviors among US youth: prevalence and association with psychosocial adjustment. JAMA. 2001;285:2094-2100.

4. Rigby K. Effects of peer victimization in schools and perceived social support on adolescent well-being. J Adolesc. 2000;23:57-68.

5. Bond L, Carlin JB, Thomas L, et al. Does bullying cause emotional problems? A prospective study of young teenagers. BMJ. 2001;323: 480-484.

6. Holt MK, Vivolo-Kantor AM, Polanin JR, et al. Bullying and suicidal ideation and behaviors: a meta-analysis. Pediatrics. 2015;135: e496-e509.

7. Takizawa R, Maughan B, Arseneault L. Adult health outcomes of childhood bullying victimization: evidence from a five-decade longitudinal British birth cohort. Am J Psychiatry. 2014;171:777-784.

8. Moore SE, Scott JG, Thomas HJ, et al. Impact of adolescent peer aggression on later educational and employment outcomes in an Australian cohort. J Adolesc. 2015;43:39-49.

9. Ttofi MM, Farrington DP. Effectiveness of school-based programs to reduce bullying: a systematic and meta-analytic review. J Exp Criminol. 2011;7:27-56.

10. Espelage DL, Hong JS, Rao MA, et al. Associations between peer victimization and academic performance. Theory Pract. 2013;52: 233-240.

11. Kochenderfer BJ, Ladd GW. Peer victimization: cause or consequence of school maladjustment? Child Dev. 1996;67:1305-1317.

12. Nakamoto J, Schwartz D. Is peer victimization associated with academic achievement? A meta-analytic review. Soc Dev. 2010;19: 221-242.

13. Balfanz R, Herzog L, Mac Iver DJ. Preventing student disengagement and keeping students on the graduation path in urban middle-grades schools: early identification and effective interventions. Educ Psychol. 2007;42:223-235.

14. Busch V, Laninga-Wijnen L, Schrijvers AJ, et al. Associations of health behaviors, school performance and psychosocial problems in adolescents in The Netherlands. Health Prom Int. 2017;32: 280-291. dav058.

15. Nowell A, Hedges LV. Trends in gender differences in academic achievement from 1960 to 1994: an analysis of differences in mean, variance, and extreme scores. Sex Roles. 1998;39:21-43.

16. Schwartz D, Gorman AH, Nakamoto J, et al. Victimization in the peer group and children's academic functioning. J Educ Psychol. 2005;97: 425.

17. Juvonen J, Nishina A, Graham S. Peer harassment, psychological adjustment, and school functioning in early adolescence. J Educ Psychol. 2000;92:349.
18. Sirin SR. Socioeconomic status and academic achievement: a metaanalytic review of research. Rev Educ Res. 2005;75:417-453.

19. Tippett N, Wolke D. Socioeconomic status and bullying: a meta-analysis. Am J Public Health. 2014;104:e48-e59.

20. Mundy LK, Simmons J, Allen NB, et al. Study protocol: the Childhood to Adolescence Transition Study (CATS). BMC Pediatrics. 2013;13:160.

21. Australian Bureau of Statistics. Schools, Australia, 2013. Available at: http://www.abs.gov.au/AUSSTATS/abs@.nsf/DetailsPage/4221. 02013. Accessed June 1, 2017.

22. Australian Curriculum Assessment and Reporting Authority. NAPLAN Achievement in Reading, Persuasive Writing, Language Conventions and Numeracy: National Report for 2012. Sydney, Australia: ACARA; 2012.

23. Bond L, Wolfe S, Tollit M, et al. A comparison of the Gatehouse Bullying Scale and the peer relations questionnaire for students in secondary school. J Sch Health. 2007;77:75-79.

24. Solberg ME, Olweus D. Prevalence estimation of school bullying with the Olweus Bully/Victim Questionnaire. Aggressive Behav. 2003;29:239-268.

25. Australian Bureau of Statistics. Census of Population and Housing: Socio-Economic Indexes for Areas (SEIFA), Australia; 2011. Available at: http://www.abs.gov.au/ausstats/abs@.nsf/mf/2033.0.55.001. Accessed June 1, 2017.

26. Goodman R. Psychometric properties of the strengths and difficulties questionnaire. J Am Acad Child Adolesc Psychiatry. 2001;40: $1337-1345$.

27. Litwiller BJ, Brausch AM. Cyber bullying and physical bullying in adolescent suicide: the role of violent behavior and substance use. $J$ Youth Adolesc. 2013;42:675-684.

28. Cross D, Shaw T, Hearn L, et al. Australian Covert Bullying Prevalence Study (ACBPS). Perth: Child Health Promotion Research Centre, Edith Cowan University; 2009.

29. Björkqvist K, Lagerspetz KM, Kaukiainen A. Do girls manipulate and boys fight? Developmental trends in regard to direct and indirect aggression. Aggressive Behav. 1992;18:117-127.

30. Arseneault L, Walsh E, Trzesniewski K, et al. Bullying victimization uniquely contributes to adjustment problems in young children: a nationally representative cohort study. Pediatrics. 2006;118: $130-138$.

31. Wang W, Vaillancourt T, Brittain HL, et al. School climate, peer victimization, and academic achievement: results from a multiinformant study. Sch Psychol Q. 2014;29:360-377.

32. Rothon C, Head J, Klineberg E, et al. Can social support protect bullied adolescents from adverse outcomes? A prospective study on the effects of bullying on the educational achievement and mental health of adolescents at secondary schools in East London. J Adolesc. 2011;34:579-588.

33. Juvonen J, Graham S, Schuster MA. Bullying among young adolescents: the strong, the weak, and the troubled. Pediatrics. 2003;112: $1231-1237$.

34. Eisenberg ME, Neumark-Sztainer D, Perry CL. Peer harassment, school connectedness, and academic achievement. J Sch Health 2003; 73:311-316.

35. Mundy LK, Canterford L, Tucker D, et al. Academic performance in primary school children with common emotional and behavioral problems. J Sch Health. 2017;87:593-601.

36. Holt MK, Greif Green J, Reid G, et al. Associations between past bullying experiences and psychosocial and academic functioning among college students. J Am Coll Health. 2014;62:552-560.

37. Rigby K, Slee P. Interventions to reduce bullying. Int J Adolesc Med Health. 2008;20:165-183. 